\title{
Monotherapy with methotrexate for primary central nervous lymphoma has single agent activity in the absence of radiotherapy: a single institution cohort
}

\author{
Julien Cobert · Ephraim Hochberg • \\ Nina Woldenberg • Fred Hochberg
}

Received: 27 October 2009/Accepted: 30 November 2009/Published online: 18 December 2009

(C) The Author(s) 2009. This article is published with open access at Springerlink.com

\begin{abstract}
We have retrospectively reviewed toxicities and response of a cohort of primary central nervous system lymphoma (PCNSL) patients treated with high dose parenteral methotrexate (MTX) monotherapy without whole brain radiation. From The Massachusetts General Hospital (MGH) Cancer Registry, active since 1946, we selected all immunocompetent patients with histologic and/or radiographic PCNSL diagnosed between 1980 and 2007. We identified the recipients of MTX with leucovorin rescue as sole therapy. No patient received radiation therapy (XRT). We analyzed this cohort for toxicity, response and patterns of recurrence. The cohort of 121 patients received on average 11 cycles of intravenous MTX at a median dose of $8 \mathrm{~g} / \mathrm{m}^{2}$. Median interval between cycles was 10 days. After 3 months of therapy, the overall response rate was $85 \%$ (58\% CR, $27 \%$ $\mathrm{PR}$ ). The overall survival (OS) for the cohort was 7 years and progression-free survival (PFS) was 3.14 years. A trend toward a higher PFS was seen in patients who continued to receive MTX (3.48 years) every three months as compared
\end{abstract}

J. Cobert

Duke University School of Medicine, 200 Trent Drive, Durham, NC 27710, USA

e-mail: jmcobert@gmail.com

E. Hochberg

Massachusetts General Hospital Cancer Center, 55 Fruit Street, YAW 7E, Boston, MA 02114, USA

N. Woldenberg

Case Western Reserve University School of Medicine,

2109 Adelbert Road, Cleveland, OH 44106, USA

F. Hochberg $(\bowtie)$

Stephen E. and Catherine Pappas Center for Neuro-Oncology,

55 Fruit Street, YAW 9E, Boston, MA 02114, USA

e-mail: FHochberg@ partners.org; fhochberg@ rcn.com to patients who ceased MTX after one year (2.86 years). Of 68 patients who achieved initial CR, there were 40 recurrences. Twenty-six of the 40 were re-induced with MTX as above; Sixty-nine percent again achieved CR. Eighty-one treatment-related toxicities occurred in 1316 MTX cycles. These toxicities included MRI white matter changes $(N=8)$ and lead to MTX cessation in 16 patients. High-dose MTX monotherapy of PCNSL is well-tolerated and provides PFS of $>3$ years and $\mathrm{OS}>7$ years.

Keywords Methotrexate (MTX) - PCNSL . Chemotherapy $\cdot$ Lymphoma

\section{Introduction}

The rise in prevalence of primary central nervous system lymphoma has provided the base for accrual to novel therapies as well as evidence-based treatment options. In general, over half of primary central nervous system lymphoma (PCNSL) patients achieve complete response therapy with overall survival exceeding two years [1]. Anti-folate agents, developed at the NCI in the 1960's, demonstrated activity in tumor cell screening assays [2, 3] and in treatment of systemic B cell lymphoma [4-6]. Methotrexate (MTX) was adopted to treat PCNSL as unlikely to cause significant myelosuppression or white matter toxicity [7]. It's benefit could be seen with deferred radiotherapy (XRT). Parenteral MTX was provided either as two or more cycles prior to XRT [8,9] or in combination with other agents [10]. Intent-to-treat studies utilizing single agent MTX were performed by the consortiums NABTT [11] and NOA [12, 13] and evaluated in the elderly [14]. The NABTT and meta-analyses that have been performed underscore MTX benefit with CR rates in 
excess of $50 \%$; while the NOA study did not. We have retrospectively reviewed our single institution experience in treating PCNSL. These data serve as a baseline against which future therapeutic strategies can be compared.

\section{Methods}

\section{Cohort ascertainment}

The Massachusetts General Hospital Cancer Registry since 1946 records all newly confirmed malignant tumors diagnosed. These data are archived in an IRB-approved database and an electronic medical record system. We queried this database for records of patients with PCNSL treated at the Massachusetts General Hospital (MGH) between January 1, 1980 and August 1, 2007. We included non-Hodgkin's lymphoma ("Large-cell lymphoma", "immunoblastic lymphoma" and "NHL of nervous system") [15] of the central nervous system confirmed by pathologic examination. Pathologic diagnoses were not re-confirmed. All patients had mass lesions (MRI) of brain, ventricles or meninges in the setting of pathologic confirmation of lymphoma of brain parenchyma, CSF, nerve roots and/or spinal cord, or clonal immunoglobulin gene rearrangement [16], flow cytometry, or cytologic ("atypical" or "suspicious" or "malignant") abnormalities of cells from CSF or vitreous. We included patients with confirmed involvement of brain, CSF, nerve or spinal cord, in the setting of previous intraocular lymphoma (PIOL), as well as PCNSL patients who later relapsed in brain or CSF. We excluded patients lacking histologic confirmation. immunocompromised patients; those with HIV positivity or recipients of organ transplant, those with CNS low-grade lymphoma or acute leukemia, systemic lymphoma (NHL) with spread to the central nervous system. We recorded comorbidities.

\section{Treatment}

Of 209 PCNSL patients we selected 121 whose first therapy was HD-MTX every ten-14 days) [11, 17]. Of these 67 have been the subject of reports $[7,9,11]$. We excluded those with multi-drug chemotherapy that was MTX-based; recipients of $\geq 5$ standard fractions of whole-brain irradiation (WBXRT) or recipients of alternative dosing schedules of MTX. Prior to 1995, MTX was provided to nine patients at dose level $3.5 \mathrm{~g} / \mathrm{sq} . \mathrm{m}$. Thereafter dosing was $8 \mathrm{~g} / \mathrm{sq} . \mathrm{m}$. every ten to fourteen days until disease progression or CR. A subgroup of $\mathrm{CR}$ patients continued to receive MTX every month for three cycles and then every three months thereafter ("maintenance"). MTX dosing for all patients was adjusted to pre-treatment calculated or measured glomerular filtration rate. Leucovorin calcium rescue $(25 \mathrm{mg}$ every $6 \mathrm{~h}$ ) was initiated $24 \mathrm{~h}$ after the start of MTX infusion and continued until $24 \mathrm{~h}$ after MTX levels fell below $<.25 \mathrm{mcM} / \mathrm{l}$. No complete responder received further corticosteroids.

\section{Outcome measures}

We sought to determine the benefit of MTX therapy for PCNSL of brain. We defined the date of progression as the date (after CR or PR) of provision of the next form of systemic chemotherapy. These treatments at recurrence included retreatment with MTX (systemic MTX, or alternative route MTX: intrathecal, intravitreal, "intraocular"), drugs other than MTX, radiation therapy (to whole brain or localized radiosurgery [SRS] or spine). All 121 patients had radiographic measurable disease. Case ascertainment is depicted in Fig. 1.

\section{Toxicity}

We recorded adverse events that resulted in delay, reduction or cessation of MTX therapy. These included $>$ grade 2 CTC toxicities (NCI toxicity criteria), leukoencephalopathy (in the absence of gadolinium-enhancing tumor); leukopenia (White blood cell count $\leq 3,000$ or $\mathrm{ANC} \leq 1,500$ ); thrombocytopenia (Platelet counts $\leq 75,000$ ); azotemia (Creatinine $\geq 1.5 \times \mathrm{ULN}$ ); anaphylactic reaction or generalized eruption; hepatic dysfunction (SGOT or Alkaline phosphatase elevation $>2.5 \times \mathrm{ULN}$ ) ; or newly appearing changes in cognition or sensation. We defined leukoencephalopathy $>$ grade 2 (moderate increase in subarachnoid space (SAS); and/or moderate ventriculomegaly; and/or focal flair or $\mathrm{T} 2$ hyperintensities extending into centrum ovale; or involving $1 / 3$ to $2 / 3$ of susceptible areas of cerebrum) and identified patients with $10 \%$ decrement in Mini-mental status exam as performed every two weeks prior to $\mathrm{CR}$ and every two months thereafter).

\section{Response to therapy}

Response to therapy, based upon two-dimensional measurements of gadolinium enhancing mass(es) on MRI or CT (if MRI contraindicated) at bi-monthly intervals included: Complete response ([CR]—complete absence of gadolinium enhancing mass(es)), Partial response ([PR]less than complete reduction of enhancing mass(es)), Mixed response ([MR]—variable change of multiple masses including progression with concomitant PR or CR), Stable disease ([SD] - No change in size of a mass), Progressive disease ([PD]-increased diameter of enhancing gadolinium mass(es)). Persisting enhancement at the prior biopsy site was not viewed as progression. We recorded the date of best response after start of MTX as well as the sites of failure. 
Fig. 1 Schematic of case ascertainment. NHL nonHodgkin lymphoma, $d x$ diagnosis, $I O L$ intra-ocular lymphoma, $P C N S L$ primary central nervous system lymphoma, CHT chemotherapy, MTX methotrexate, WBXRT whole-brain radiation therapy

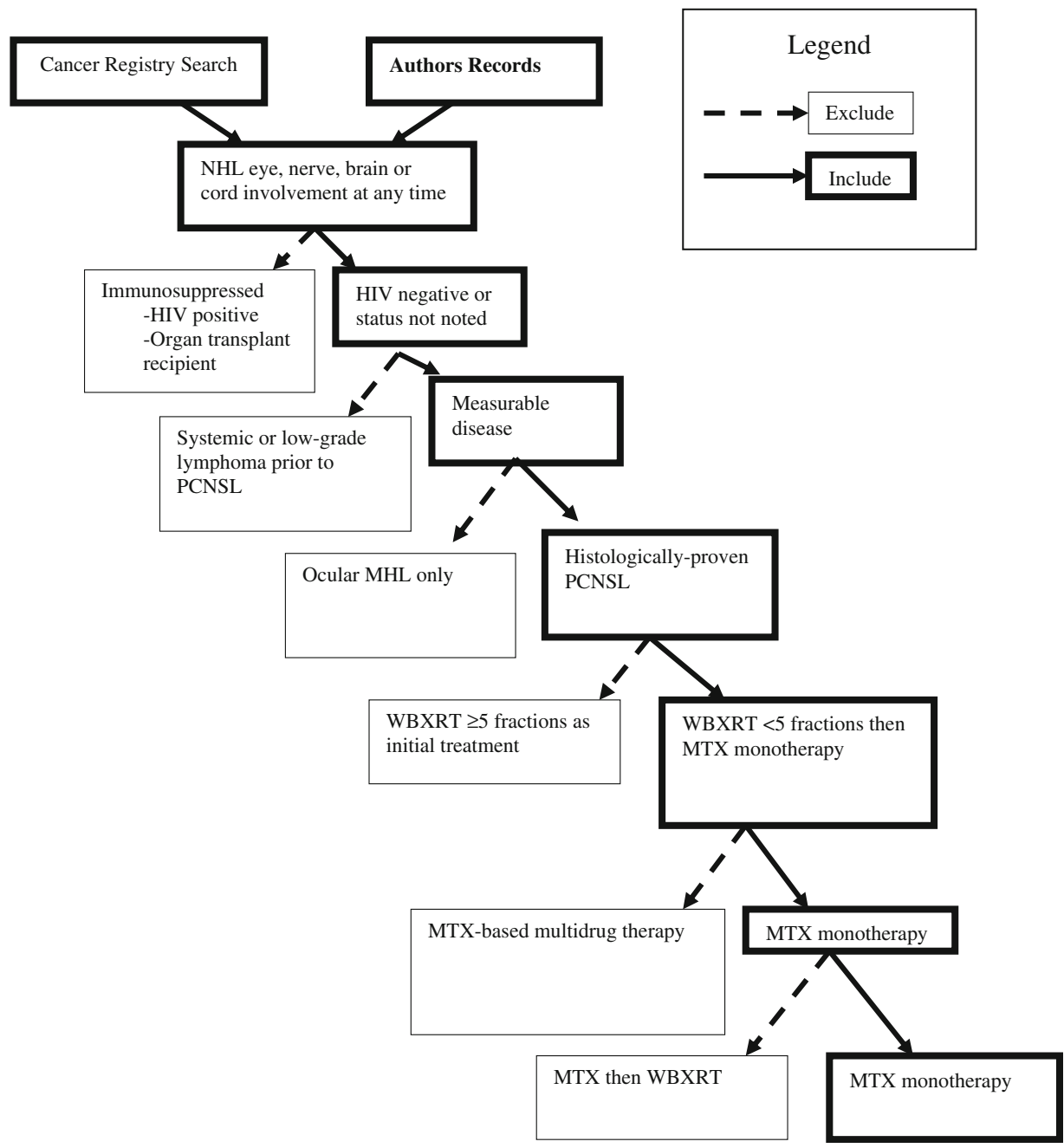

Data analysis

We recorded patient age, gender, annualized risk of PCNSL, patient comorbidities, drug toxicities and response to therapy. Patients were not contacted and thus we recorded the interval from diagnosis to last follow-up. Patients lost to follow-up after Cycle 1 MTX, were assigned survival of "zero" months. Their toxicity data were recorded. We calculated progression-free survival (PFS) and overall survival (OS) for all patients.

\section{Results}

209 patients were diagnosed with primary central nervous system lymphoma between January 1, 1980 and August 1, 2007. The case-incidence peak occurred 1996-2000. One hundred twenty-one patients received MTX monotherapy, of whom 117 had data for survival evaluation (Fig. 2).

Demographics

The median age of the 121 patients was 63 years (range 2386 years). Males predominated (53\%). Brain parenchymal involvement was most common (94\%) including $11 \%$ with brain and another nervous system site. Six percent of patient had CSF involvement with nodular measurable disease. Comorbidity included: lupus erythematosus prior MTX therapy (one for "breast cancer" and one for unconfirmed "ocular lymphoma"), renal insufficiency (2), idiopathic thrombocytopenic purpura (2), polyglandular autoimmune syndrome E type 1 (1), steroid use (10), non-brain radiation therapy for systemic malignancy (3) and ocular lymphoma [4]), prior chemotherapy (7) and Lyme disease (2). 
Fig. 2 Responses to MTX monotherapy. $C R$ complete response, $P D$ progressive disease, $P R$ partial response, $M R$ mixed response, $S D$ stable disease

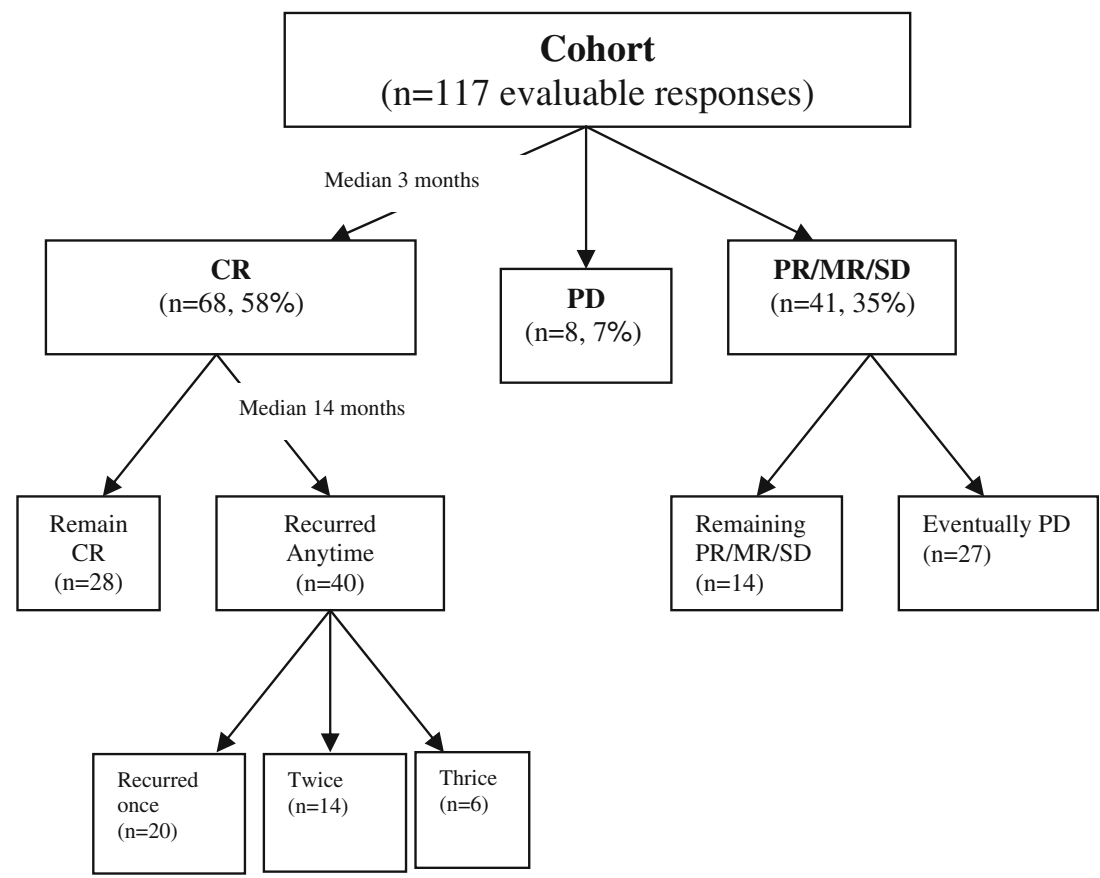

Response to therapy

Of 121 patients, $106(87.6 \%)$ initially received MTX at a dose of $8 \mathrm{~g} / \mathrm{m}^{2}$ and fifteen $(12.4 \%$ ) received doses of $3.5 \mathrm{~g} /$ $\mathrm{m}^{2}$ or less. Response was not evaluable in four patients due to: missing MRI (1 patient), lost to follow-up (1), cessation of MTX prior to response evaluation (2). An additional patient, evaluable for response, died of progressive lymphoma prior to MTX therapy. The overall response rate to Methotrexate induction was $85 \%$ (100/117). CR occurred in $58 \%\left(58.5 \%\right.$ of patients treated at MTX $8 \mathrm{~g} / \mathrm{m}^{2}$ and $50 \%$ at MTX $3.5 \mathrm{~g} / \mathrm{m}^{2}$ ). CR was achieved after a median of 6 cycles of therapy over an elapsed time of 3 months. Twenty-seven percent of patients had PR, 7\% PD, 5\% SD, and 3\% MR. Patients who did not achieve a CR rapidly progressed. Twenty-seven of the 41 patients who achieved PR, SD or MR, progressed after two more cycles of MTX (one month) (Fig. 2).

Six PCNSL patients had MRI measurable tumor in the setting of CSF with "atypical" or "suspicious" cells. Five of these achieved CR (2-9 cycles MTX), and one progressed ( 1 cycle). Three patients additionally received at least one cycle of intrathecal therapy and five received intravitreal therapy.

The median overall survival (53 deaths and 68 censored) was 7 years $(95 \%$ CI of $4.6,12.8)$. The survival rates at $1,>5$ and 10 years were 86,58 and $44 \%$ respectively (Fig. 3, OS). For patients achieving CR, the median progression-free survival was 3.14 years $(95 \%$ CI of 2.48 , 5.18) (Fig. 4, PFS). Thirty percent of the entire cohort progressed during therapy with MTX (Table 1). Forty

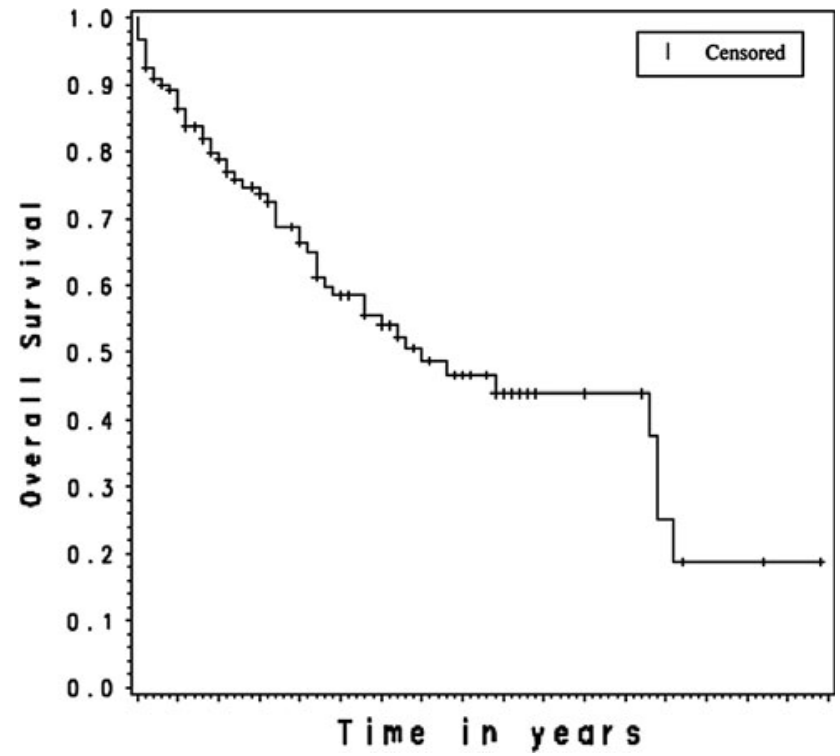

Fig. 3 Overall survival of cohort $(n=121)$. Of 121 patients in the cohort, 53 patients died and 68 survived. The median OS was 7 years with $95 \%$ CI $4.6,12$. The 1,5 and 10 year OS rates were 86,58 and $44 \%$ respectively. TTP time to progression, $95 \%$ CI $95 \%$ confidence interval

additional patients (59\% of those with CR) recurred 14 months (IQR 6.75, 32.5) after complete response. Patients in CR who continued MTX at least one year further fared better than those who stopped within two cycles of CR. Progression-free survival for the former was 3.48 years (95\% CI of 2.16, 5.8; Fig. 4), versus 2.86 years (95\% CI of 1.32 and upper bound not reached; Fig. 4) for 


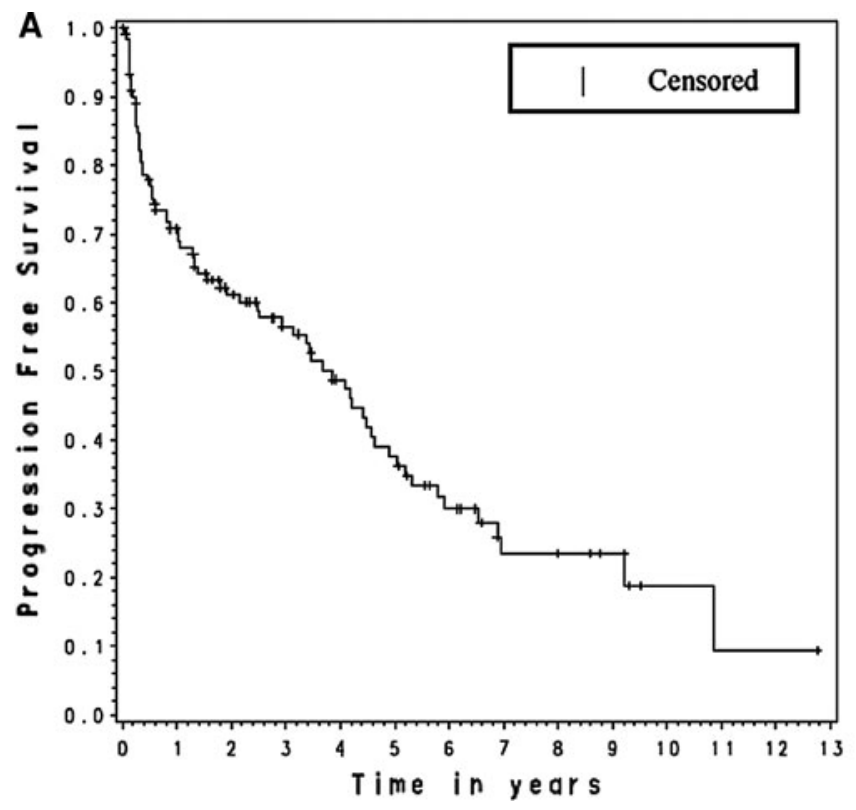

Fig. 4 Progression-free survival. a PFS of CR patients $(n=68)$ - Of 68 patients achieving $\mathrm{CR}$, forty progressed, while 28 (censored) remained progression-free. The median PFS was 3.14 years with $95 \%$ CI of $(2.48,5.18)$. The 1,5 and 10 years PFS rates were 87,51 and $38 \%$, respectively; b PFS by MTX continuation after CR-For patients who ceased MTX within two cycles of CR (dotted line), the

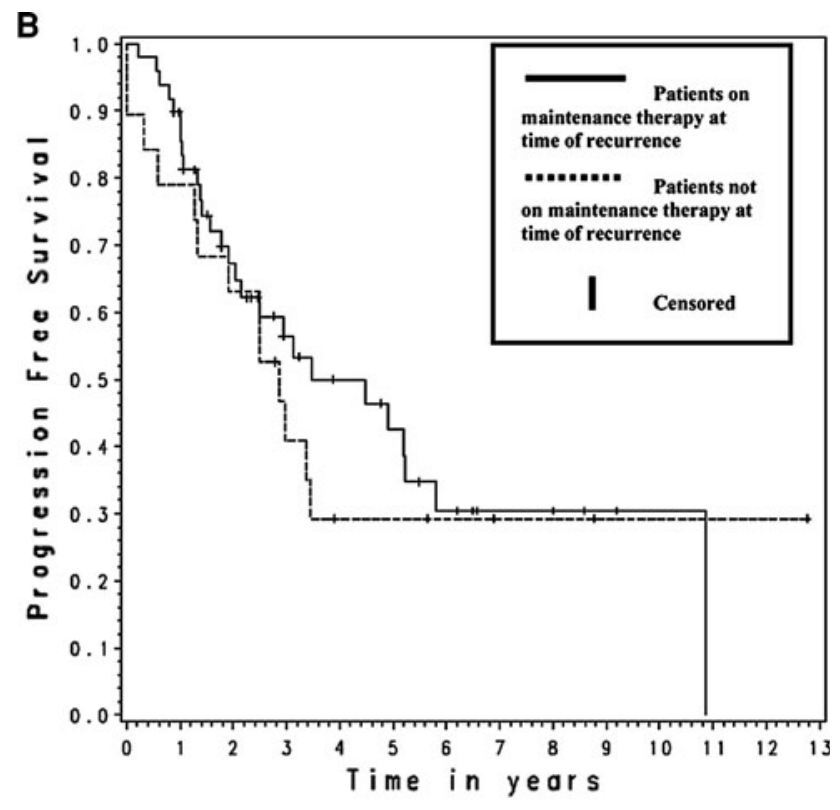

median PFS is 2.86 years with $95 \%$ CI of (1.32, upper not reached). The 1,2 and 5 years rate are 79,63 , and $29 \%$ respectively. For patients who continued MTX after CR (solid line), the median PFS is 5 years with $95 \% \mathrm{CI}$ of $(3,9.2)$. The 1,2 and 5 years rate are 90 , 67 , and $43 \%$ respectively. PFS progression-free survival; $95 \% C I$ $95 \%$ confidence interval

Table 1 Recurrence after MTX therapy $(n=117)$

\begin{tabular}{|c|c|c|c|c|c|c|c|c|}
\hline Refs. & No. & Dose MTX $\mathrm{g} / \mathrm{m}^{2}$ & Frequency & Cycles to response & CR $(\%)$ & $\mathrm{PD} / \mathrm{SD}(\%)$ & PFS (months) & OS (months) \\
\hline [12] & 37 & 8 & Biweekly & 6 & 29.7 & 37.8 & 13.7 & 25 \\
\hline [14] & 10 & 8 then 3.5 & Every 14 days, 3 cycles & 9 & 60 & 10 & 18 & 20 \\
\hline$[23]$ & 20 & 8 then WBXRT & q 14-21 days & 2 & 50 & 25 & N/a & N/a \\
\hline [41] & 23 & 8 & q. 14 days then WBXRT & & & & $6^{+}$ & $17^{+}$ \\
\hline$[42]$ & 4 & $400 \mu \mathrm{g}$ (intravitreally) & q. 2 weeks & Median 7 & 100 & 0 & & \\
\hline$[43]$ & 28 & $100 \mathrm{mg} / \mathrm{kg}$ over $3 \mathrm{~h}$ & Then WBXRT & & 11 & 21 & & \\
\hline
\end{tabular}

$P D$ progressive disease, $C R$ complete response, $M T X$ methotrexate, $I Q R$ inter-quartile range

the latter. Recurrences occurred in brain $(68 \%)$, vitreous (5), systemic sites (5), nerve root (2) and CSF (1). Of sixtythree deaths (through August 1, 2007), 63\% resulted from PCNSL. No deaths were attributable to drug toxicity.

Of CR patients, 40 ultimately recurred including twenty patients with one recurrence, fourteen with two sequential recurrences, and six with three recurrences. Twenty-six patients with relapsed PCNSL were treated again with MTX monotherapy. Eighteen (69\%) again achieved CR and one achieved PR.

MTX-toxicities included eighty-one events. Sixteen of these led to drug cessation and 14 to MTX dose reduction or delay. Toxicities included leukoencephalopathy (8) (including full-scale IQ decrement by 30 points which led to MTX cessation); reversible azotemia (21 patients) (of which four led to MTX cessation and three to dose delay or
Table 2 Literature reports of MTX monotherapy

\begin{tabular}{ll}
\hline Recurrences & $\begin{array}{l}\text { Number of patients } \\
\text { (\% of entire cohort) }\end{array}$ \\
\hline $\begin{array}{l}\text { Pts with PD at any time } \\
\text { Patients recurring }\end{array}$ & $35(29.9 \%)$ \\
Once & $20 \%$ \\
Twice & $14 \%$ \\
Three times or more & $6 \%$ \\
$C R s$ who recurred & $58.8 \%$ \\
Median time from CR to recurrence & 14 months \\
Recurrence while receiving MTX & 27 of 49 patients \\
Recurrence while NOT receiving MTX & 13 of 19 patients \\
\hline
\end{tabular}

Ref reference, MTX methotrexate, iv intravenous, WBXRT wholebrain radiation therapy, $C R$ complete response, $P D$ progressive disease, $S D$ stable disease, $P F S$ progression-free survival, $O S$ overall survival, $F U$ follow-up 


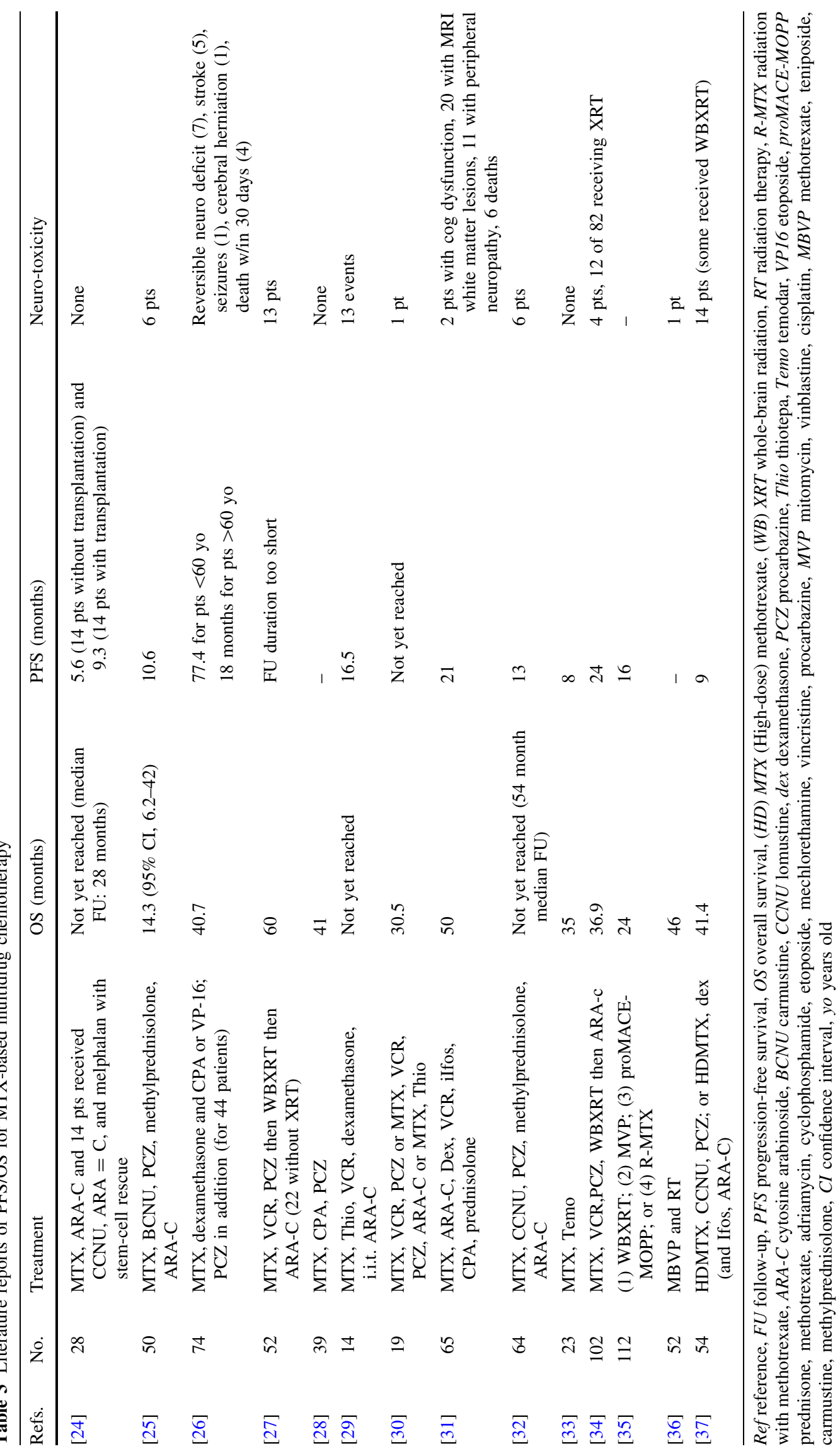


reduction). MTX was continued in four patients despite elevated liver enzymes (LFT) including one MTX delay. The 18 occurrences of leukopenia led to drug cessation (1) dose delays (2) while thrombocytopenia (16) did not. Sixteen cutaneous drug reactions, included a fixed drug reaction, did not require discontinuation; but one anaphylactic reaction led to drug cessation. Nine patients ceased MTX therapy as a result of sepsis (2), renal failure (2), mucositis (2), pulmonary emboli, clostridium gastroenteritis and drug-resistant tachycardia.

\section{Discussion}

We report a single-site cohort provided MTX monotherapy for PCNSL. The therapy provided CR or PR response in $85 \%$ and PFS of 3.14 years. The overall survivals of $86 \%$ at one year, $58 \%$ at five years and $44 \%$ at 10 years- are likely low as we assumed death to have occurred on the date of last follow-up. These data will well serve investigators describing the benefits to PCNSL patients of novel immunologic or stem cell therapies. Despite initial MTX responses (CR, PR, MR, SD); 30\% of the 117 patients progressed within 15 months. We were unable to establish, as has been reported by Ferreri [18], a metric to separate eventual responders from non-responders despite evaluating (unpublished) the prognostic roles of demography, number and volume of brain lesions, pre-therapy performance status and MTX pharmacokinetics. Recent studies [19] suggest correlates of MTX efficacy and toxicity including pharmacogenomic analyses as well as assays of the expression of folate carrier channels [20, 21].

Toxicities of MTX were rare and reversible. Sixty-eight percent of recipients experienced no toxicity; but seven MTX-related toxic events led to MTX cessation. These included: leukoencephalopathy, azotemia, leucopenia, anaphylaxis, sepsis, and mucositis. This low rate reflects care provided by neurologic and chemotherapy nurses with experience in the provision of hydration in the setting of brain edema, the knowledge of drug-MTX interactions and experience in the provision of "accelerated" calcium leucovorin emerging during azotemia or the release of MTX from "third-spaces". These toxicities have been well documented [22].

Our CR rate of $58 \%$ is similar to other reports (Table 2) including Watanabe [23] $(\mathrm{CR}=50 \%)$ and $\mathrm{Ng}$ [14] (CR6/ $10)$; but unlike that of Herrlinger [13] $(\mathrm{CR}=30 \%)$. Uncertain is whether differences reflect the comorbidity of patients or intricacies of MTX administration.

Three months after starting MTX therapy patients can be declared "responders" or "non-responders". By this evaluation (6 cycles MTX) CR was identified in 58\% of patients; PD was declared somewhat earlier (2 months).
Thus 3 months of MTX therapy represents a baseline against which investigators may evaluate the efficacy of adding other agents. MTX-monotherapy is not curative. Progression of disease was seen in sixty-six percent of patients with PR, MR or SD and in 59\% of those with CR. Uncertain is whether continuation of MTX-monotherapy prolongs PFS. The PFS for CR patients who continued MTX every three months was 3.48 years in comparison to 2.86 years for those who ceased MTX within the first year and similar patients reported by others $[12,14]$. These recurrences do not reflect resistance to MTX; as CR followed MTX-monotherapy retreatment in eighteen of 26 PCNSL patients who had relapsed. Although MTX-based multi-drug/irradiation therapies (Table 3) are associated with PFS rates ranging from 5.6 months [24] (Cytarabine, Carmustine, etoposide, melphalan with stem cell rescue) to 11 months [25] (Lomustine, procarbazine, Cytarabine and methylprednisolone) to 77.4 months [26] (receiving steroids, cyclophosamide or etoposide and procarbazine) it is unlikely that these approaches will be the subject of randomized trials in comparison to MTX-monotherapy. The multi-drug therapies [24-37] overall survivals are 60 months [5, 27] 50 months [31] 7 months [26] similar to those we report.

Promising preliminary data suggest efficacy of adding to MTX the drugs Temodar [33] and Rituxan [38]; the provision of autologous stem cell transplantation $[39,40]$ and low dose brain radiation. These trials are ongoing. Our data provide a benchmark by which to measure the additive value of these approaches. Certainly stem cell transplantation appears a logical addition by which to consolidate the MTX-related CR seen in almost $60 \%$ of our MTX recipients. Our early experience with MTX and Temodar and Rituxan points to a reduced interval from diagnosis to CR.

Acknowledgment We would like to thank Alona Muzikansky for her help with statistical studies.

Open Access This article is distributed under the terms of the Creative Commons Attribution Noncommercial License which permits any noncommercial use, distribution, and reproduction in any medium, provided the original author(s) and source are credited.

\section{References}

1. Bessell EM, Hoang-Xuan K, Ferreri AJ et al (2007) Primary central nervous system lymphoma: biological aspects and controversies in management. Eur J Cancer 43:1141-1152

2. Bradner WT (1966) Pindell MH: myeloid leukemia C-1498 as a screen for cancer chemotherapeutic agents. Cancer Res 26:375390

3. Bertino JR (1967) Johns DG: folate antagonists. Annu Rev Med $18: 27-34$ 
4. Canellos GP, Lister TA (1978) Skarin AT: chemotherapy of the non-Hodgkin's lymphomas. Cancer 42:932-940

5. Ziegler JL (1971) Bluming AZ: intrathecal chemotherapy in Burkitt's lymphoma. Br Med J 3:508-512

6. Skarin AT, Zuckerman KS, Pitman SW et al (1977) High-dose methotrexate with folinic acid in the treatment of advanced nonHodgkin lymphoma including CNS involvement. Blood 50:1039-1047

7. Cher L, Glass J, Harsh GR et al (1996) Therapy of primary CNS lymphoma with methotrexate-based chemotherapy and deferred radiotherapy: preliminary results. Neurology 46:1757-1759

8. O'Brien PC, Roos DE, Pratt G et al (2006) Combined-modality therapy for primary central nervous system lymphoma: long-term data from a Phase II multicenter study (Trans-Tasman Radiation Oncology Group). Int J Radiat Oncol Biol Phys 64:408-413

9. Guha-Thakurta N, Damek D, Pollack C et al (1999) Intravenous methotrexate as initial treatment for primary central nervous system lymphoma: response to therapy and quality of life of patients. J Neurooncol 43:259-268

10. Glass J, Shustik C, Hochberg FH et al (1996) Therapy of primary central nervous system lymphoma with pre-irradiation methotrexate, cyclophosphamide, doxorubicin, vincristine, and dexamethasone (MCHOD). J Neurooncol 30:257-265

11. Batchelor T, Carson K, O'Neill A et al (2003) Treatment of primary CNS lymphoma with methotrexate and deferred radiotherapy: a report of NABTT 96-07. J Clin Oncol 21:1044-1049

12. Herrlinger U, Schabet M, Brugger W et al (2002) German Cancer Society Neuro-Oncology Working Group NOA-03 multicenter trial of single-agent high-dose methotrexate for primary central nervous system lymphoma. Ann Neurol 51:247-252

13. Herrlinger U, Kuker W, Uhl M et al (2005) NOA-03 trial of highdose methotrexate in primary central nervous system lymphoma: final report. Ann Neurol 57:843-847

14. Ng S, Rosenthal MA, Ashley D et al (2000) High-dose methotrexate for primary CNS lymphoma in the elderly. Neuro Oncol $2: 40-44$

15. WHO (2007) international statistical classification of diseases and related health problems, 10th revision, Version for 2007

16. Baehring JM, Hochberg FH, Betensky RA et al (2006) Immunoglobulin gene rearrangement analysis in cerebrospinal fluid of patients with lymphoproliferative processes. J Neurol Sci 247:208-216

17. Gabbai AA, Hochberg FH, Linggood RM et al (1989) High-dose methotrexate for non-AIDS primary central nervous system lymphoma. Report of 13 cases. J Neurosurg 70:190-194

18. Ferreri AJ, Guerra E, Regazzi M et al (2004) Area under the curve of methotrexate and creatinine clearance are outcomedetermining factors in primary CNS lymphomas. Br J Cancer 90:353-358

19. Ranganathan P, McLeod HL (2006) Methotrexate pharmacogenetics: the first step toward individualized therapy in rheumatoid arthritis. Arthritis Rheum 54:1366-1377

20. Serra M, Reverter-Branchat G, Maurici D et al (2004) Analysis of dihydrofolate reductase and reduced folate carrier gene status in relation to methotrexate resistance in osteosarcoma cells. Ann Oncol 15:151-160

21. Ferreri AJ, Dell'Oro S, Capello D et al (2004) Aberrant methylation in the promoter region of the reduced folate carrier gene is a potential mechanism of resistance to methotrexate in primary central nervous system lymphomas. Br J Haematol 126:657-664

22. Jahnke K, Korfel A, Martus P et al (2005) High-dose methotrexate toxicity in elderly patients with primary central nervous system lymphoma. Ann Oncol 16:445-449

23. Watanabe T, Katayama Y, Yoshino A et al (2003) Long-term remission of primary central nervous system lymphoma by intensified methotrexate chemotherapy. J Neurooncol 63:87-95
24. Abrey LE, Moskowitz CH, Mason WP et al (2003) Intensive methotrexate and cytarabine followed by high-dose chemotherapy with autologous stem-cell rescue in patients with newly diagnosed primary CNS lymphoma: an intent-to-treat analysis. J Clin Oncol 21:4151-4156

25. Hoang-Xuan K, Taillandier L, Chinot O et al (2003) Chemotherapy alone as initial treatment for primary CNS lymphoma in patients older than 60 years: a multicenter phase II study (26952) of the European Organization for Research and Treatment of Cancer Brain Tumor Group. J Clin Oncol 21:2726-2731

26. McAllister LD, Doolittle ND, Guastadisegni PE et al (2000) Cognitive outcomes and long-term follow-up results after enhanced chemotherapy delivery for primary central nervous system lymphoma. Neurosurgery 46:51-60 discussion 60-1

27. Abrey LE, Yahalom J, DeAngelis LM (2000) Treatment for primary CNS lymphoma: the next step. J Clin Oncol 18:31443150

28. Dahlborg SA, Henner WD, Crossen JR et al (1996) Non-AIDS primary CNS lymphoma: first example of a durable response in a primary brain tumor using enhanced chemotherapy delivery without cognitive loss and without radiotherapy. Cancer J Sci Am 2:166-174

29. Sandor V, Stark-Vancs V, Pearson D et al (1998) Phase II trial of chemotherapy alone for primary CNS and intraocular lymphoma. J Clin Oncol 16:3000-3006

30. Freilich RJ, Delattre JY, Monjour A et al (1996) Chemotherapy without radiation therapy as initial treatment for primary CNS lymphoma in older patients. Neurology 46:435-439

31. Pels H, Schmidt-Wolf IG, Glasmacher A et al (2003) Primary central nervous system lymphoma: results of a pilot and phase II study of systemic and intraventricular chemotherapy with deferred radiotherapy. J Clin Oncol 21:4489-4495

32. Omuro AM, Taillandier L, Chinot O et al. (2006) Methotrexate (MTX), procarbazine and CCNU for primary central nervous system lymphoma (PCNSL) in patients younger than 60: can radiotherapy (RT) be deferred?, 2006 ASCO annual meeting proceedings. J Clin Oncol 24(18S)

33. Omuro AM, Taillandier L, Chinot O et al (2007) Temozolomide and methotrexate for primary central nervous system lymphoma in the elderly. J Neurooncol 85:207-211

34. DeAngelis LM, Seiferheld WS, Schold SC et al (2002) Combination chemotherapy and radiotherapy for primary central nervous system lymphoma: radiation therapy oncology group study 93-10. J Clin Oncol 20:4638-4643

35. Yamanaka R, Morii K, Shinbo Y et al (2008) Results of treatment of 112 cases of primary CNS lymphoma. Jpn J Clin Oncol 38:373-380

36. Poortmans PM, Kluin-Nelemans HC, Haaxma-Reiche $\mathrm{H}$ et al (2003) High-dose methotrexate-based chemotherapy followed by consolidating radiotherapy in non-AIDS-related primary central nervous system lymphoma: European Organization for Research and Treatment of Cancer Lymphoma Group Phase II Trial 20962. J Clin Oncol 21:4483-4488

37. Kiewe P, Fischer L, Martus P et al (2008) Primary central nervous system lymphoma: monocenter, long-term, intent-to-treat analysis. Cancer 112:1812-1820

38. Yamanaka R, Homma J, Sano M et al (2007) Immuno-chemotherapy with a combination of rituximab, methotrexate, pirarubicin and procarbazine for patients with primary CNS lymphoma-a preliminary report. Leuk Lymphoma 48:10191022

39. Illerhaus G, Marks R, Ihorst G et al (2006) High-dose chemotherapy with autologous stem-cell transplantation and hyperfractionated radiotherapy as first-line treatment of primary CNS lymphoma. J Clin Oncol 24:3865-3870 
40. Illerhaus G, Muller F, Feuerhake F et al (2008) High-dose chemotherapy and autologous stem-cell transplantation without consolidating radiotherapy as first-line treatment for primary lymphoma of the central nervous system. Haematologica. 93:147-148

41. Shenkier TN, Voss N, Chhanabhai M et al (2005) The treatment of primary central nervous system lymphoma in 122 immunocompetent patients: a population-based study of successively treated cohorts from the British Colombia Cancer Agency. Cancer 103:1008-1017
42. Fishburne BC, Wilson DJ, Rosenbaum JT et al (1997) Intravitreal methotrexate as an adjunctive treatment of intraocular lymphoma. Arch Ophthalmol 115:1152-1156

43. Hiraga S, Arita N, Ohnishi T et al (1999) Rapid infusion of highdose methotrexate resulting in enhanced penetration into cerebrospinal fluid and intensified tumor response in primary central nervous system lymphomas. J Neurosurg 91:221-230 